\title{
Democracia e gestão democrática em sistemas municipais de ensino: a realidade do estado do Paraná
}

\author{
Democracy and democratic management in municipal education systems: the \\ reality of the state of Paraná
}

Democracia y gestión democrática en los sistemas de educación municipal: la realidad del estado de Paraná

SIMONE DE FÁTIMA FLACH

ORCID iD: http://orcid.org/0000-0002-9445-0111

Universidade Estadual de Ponta Grossa.

\begin{abstract}
Resumo: A partir do materialismo histórico e dialético, este artigo tem por objetivo desvelar como o princípio constitucional da gestão democrática do ensino público se faz presente nas políticas locais. Para tanto, o texto tece considerações a respeito dos fundamentos da democracia e sua relação com a gestão democrática; apresenta algumas possibilidades e alguns limites para a sua efetivação na realidade paranaense e, por fim, analisa dados de pesquisa em municípios que já instituíram sistemas municipais de ensino.
\end{abstract}

Palavras-chave: Gestão democrática; Sistema Municipal de Ensino; políticas educacionais municipais.

\begin{abstract}
From the historical and dialectical materialism, this paper aims to reveal how the constitutional principle of democratic management of public education is present in local policies. To this end, this text makes considerations on the foundations of democracy and its relation to democratic management; it presents some possibilities and some limits for its effectiveness in the Parana reality and, finally, it analyzes research data in municipalities that have already instituted Municipal Systems of Education.
\end{abstract}

Keywords: Democratic management. Municipal System of Education. Municipal educational policies.

Resumen: A partir del materialismo histórico y dialéctico, este artículo tiene como objetivo presentar cómo el principio constitucional de gestión democrática de la educación pública está presente en las politicas locales. Con este fin, el texto bace consideraciones sobre los fundamentos de la democracia y su relación con la gestión democrática; presenta algunas posibilidades y algunos límites para su efectividad en la realidad paranaense y, por fin, analiza los datos de investigación en municipios que ya han instituido los Sistemas Municipales de Educación.

Palabras clave: Gestión democrática. Sistema Municipal de Educación. Politicas educativas municipales. 


\section{INTRODUÇÃO}

A democracia, a democratização da educação, a gestão democrática da e na educação são conceitos historicamente construídos e estão vinculados à interpretação que se dá conforme os fundamentos que sustentam a análise em determinado momento histórico. Por isso, tratar da gestão democrática como princípio fundante para a organização e a oferta educacional em determinadas realidades requer a compreensão da dimensão contraditória do termo. Além disso, a forma como é utilizada indica sua vinculação com determinada concepção de sociedade (atual ou futura) e o compromisso com a manutenção ou transformação do status quo.

Sob a égide dos fundamentos do materialismo histórico e dialético e sob os limites da atual forma de sociabilidade, este texto apresenta a análise dos dados de uma pesquisa sobre a realidade de municípios paranaenses que já instituíram Sistemas Municipais de Ensino, com o objetivo de desvelar como o princípio constitucional da gestão democrática do ensino público se faz presente nas políticas locais.

Com o intuito de colaborar na compreensão sobre como a democracia se insere no campo educacional, utilizamos sua interpretação em dois polos controversos: a democracia liberal burguesa, sob a qual se assenta todo o aparato legal-normativo de gestão democrática do ensino público brasileiro atual; e outra forma, aqui denominada de democracia social, a qual tem a participação ampla e o compromisso em suprir as necessidades da maioria da população com seus fundamentos. Para tanto, apresentamos as bases da democracia nesses dois polos e sua vinculação com a gestão democrática do ensino no Brasil, de forma a demonstrar que, mesmo sob os limites sociais, culturais e econômicos do país, algumas possibilidades podem ser evidenciadas nas realidades locais.

Em seguida, apresentamos dados de pesquisa sobre como a gestão democrática se manifesta nas realidades locais de municípios paranaenses que já instituíram Sistemas Municipais de Ensino, evidenciando como tais realidades são contraditórias, pois, embora esses municípios declarem legalmente que exercerão sua autonomia na condução das políticas educacionais e mostrem avanços nos processos de participação e decisão no encaminhamento político-educacional municipal, há fortes indícios de ações limitadoras e cerceadoras dessa participação, seja por meio de influências locais ou por subserviência aos encaminhamentos políticos mais gerais. Tais fatos indicam que o processo decisório local se mostra carregado de interesses de grupos dominantes; desse modo, a hegemonia revelase e mostra toda a sua força na condução de políticas educacionais municipais. 
Por fim, os documentos legais e normativos que disciplinam a organização dos Sistemas Municipais de Ensino e as formas de participação da comunidade na gestão das escolas e dos órgãos de fiscalização e controle social das políticas educacionais são apresentados e analisados. As análises indicam tanto possibilidades quanto limites para a efetivação da gestão democrática no âmbito municipal, evidenciando o movimento dialético entre o singular e o universal, tal qual abordado por Cheptolin (1982).

\section{FUNDAMENTOS SOBRE DEMOCRACIA E VINCULAÇÃO COM A GESTÃO DEMOCRÁTICA DO ENSINO}

Em sociedades periféricas, como a brasileira, a democracia é frágil, pois para sobreviver inserido na lógica capitalista, o Estado age para a manutenção da exploração da classe trabalhadora, debilitando iniciativas que tenham como fundamento ampliar a participação na definição de políticas sociais com a finalidade de amenizar as desigualdades. É importante destacar que o Estado é aqui entendido na concepção gramsciana, sendo composto pela união entre sociedade política e sociedade civil, de forma que a hegemonia se faz presente nas ações estatais por meio do consenso ou da coerção. Por isso, a discussão de democracia não pode ser analisada descolada do conceito de hegemonia, pois, conforme apontado por Gramsci (2007, p. 287):

\footnotetext{
No sistema hegemônico, existe democracia entre o grupo dirigente e os grupos dirigidos na medida em que o desenvolvimento da economia e, por conseguinte, a legislação que expressa este desenvolvimento favorecem a passagem molecular dos grupos dirigidos para o grupo dirigente.
}

Essa assertiva remete às condições estruturais que possibilitem aos grupos dirigidos tornarem-se dirigentes. No entanto, é preciso questionar: "pretende-se que sempre existam governados e governantes ou pretende-se criar as condições nas quais a necessidade dessa divisão desapareça?” (GRAMSCI, 2007, p. 325). Sob o jugo do modo de produção capitalista, o desaparecimento da divisão entre governantes e governados não é algo a ser perseguido, visto que esse modo de produção se fundamenta e se mantém na divisão do trabalho e na consequente divisão social. Por conseguinte, a superação dessa divisão só será possível em outro modo e produção que tenha a igualdade e a justiça social como fundamento. No que tange à possibilidade de vivência democrática nos limites da organização social capitalista, é preciso ter claro que a democracia burguesa é uma realidade. Se, no final do século XVIII, a defesa da democracia, pautada nos princípios de liberdade, igualdade e fraternidade representou um avanço para a derrocada 
de uma determinada organização social, também representou a expressão da opressão de uma nova classe sobre a outra: os burgueses assumiram o posto de dominantes e subordinaram a classe trabalhadora à lógica desmedida de obtenção de mais valia, a partir da exploração do trabalho humano. A partir de então, a classe burguesa passou, como classe dominante, a determinar "o que pensar o que estudar e até mesmo o que e como amar" (DIAS, 2014, p. 28). Isso ocorre por um processo ideológico no qual a hegemonia de determinada classe se materializa no cotidiano dos sujeitos, de forma que os valores burgueses são realçados e as necessidades da classe dominada são minimizadas. Nesse sentido:

\begin{abstract}
Os dominados compartem o horizonte subjetivo dos dominantes, sem terem a menor chance de vivê-lo no cotidiano: quadros vitais aparentemente inconciliáveis, solidados pela ideologia da igualdade e do mérito, onde tudo é possível. Isto é ocultado e não se resolve em conflito aberto graças a um discurso universal, que ai do "sempre foi assim" até o "tem que ser assim", a partir do qual o que é violência simbólica e física vir padrão ético, eterno e universal, de comportamento que busca transformar conflito em harmonia, em parceria. Trata-se da conformação de um modo de vida, predispondo as classes trabalhadoras à servidão voluntária. (DIAS, 2014, p. 28-29, grifo do autor).
\end{abstract}

Segundo Schlesener (2018), desconsiderar a estrutura econômica da sociedade como origem das divisões políticas implica apresentar "uma definição abstrata da democracia e, consequentemente, de gestão democrática” (p. 67). A isso equivale dizer que o entendimento sobre democracia pressupõe considerar a relação entre o econômico, o político e o ideológico, sob pena de termos e defendermos uma realidade distorcida. Por isso, a discussão a respeito da democracia não pode ser unívoca, mas oferecer subsídios para o entendimento do seu significado no interior da sociedade capitalista e propor subsídios para que outras possibilidades de vivência democrática sejam possíveis, ultrapassando os efeitos da hegemonia dominante e contribuindo para a luta por outra hegemonia.

A democracia burguesa se fundamenta nos pressupostos revolucionários de igualdade, liberdade e fraternidade, sem que estes sejam amplamente compreendidos no interior da sociedade capitalista. A igualdade formal instituída pela defesa jurídica que se fundamenta na igualdade política é um misto de verdade e engano, pois, ao mesmo tempo em que coloca todos os indivíduos como pertencentes à mesma sociedade, iguais em direitos e deveres, torna a relação econômica meritocrática e não oferece as condições mínimas para a compreensão de que a igualdade econômica é nula. O pressuposto da liberdade coloca as classes sociais como livres e "iguais", de modo que o burguês é livre para comprar e o trabalhador é livre para vender a força de trabalho, obscurecendo a exploração do trabalho humano que alicerça tal relação. Por fim, o pressuposto de fraternidade 
coloca sob os ombros do trabalhador novo peso, a aceitação e a subserviência aos outros dois pressupostos, impedindo que vislumbre outra possibilidade de vida. No sentido exposto, os pressupostos de igualdade, liberdade e fraternidade naturalizam o conceito de democracia, tornando-a abstrata e impedindo que os grupos dominados percebam a injustiça que fundamenta tais pressupostos, pois retirados do contexto e naturalizados "os conceitos permitem manter uma aparência conciliadora e dificultam identificar as contradições e os interesses econômicos e políticos que subjazem a uma realidade desigual e autoritária." (SCHLESENER, 2018, p. 72).

Em que pese a democracia burguesa, no contexto do final do século XVIII ter significado avanço revolucionário, no contexto de 1870-1871, com a tentativa da Comuna de Paris, assumiu postura conservadora ao demonstrar sua "vitalidade tanto em relação ao velho como em relação o novíssimo", pois "derrota os representantes da velha sociedade que não quer confessarse definitivamente superada, mas derrota também os novíssimos grupos que consideram já ultrapassada a nova estrutura surgida da transformação iniciada em 1789.” (GRAMSCI, 2007, p. 39).

Desde o seu início, a sociedade capitalista, fundamentada nos pressupostos burgueses, mesmo tendo passado por momentos de tensão e de crises, demonstra toda a sua vitalidade agindo em todos os espaços possíveis para a manutenção de sua hegemonia. Nesse sentido, a classe burguesa "põe-se a si mesma como um organismo em contínuo movimento, capaz de absorver toda a sociedade, assimilando-a a seu nível cultural e econômico." (GRAMSCI, 2007, p. 271). Assim, ao exercer a hegemonia, a burguesia detém o poder estatal e consegue determinar o aparato jurídico-normativo que visa assegurar a democracia, uma vez que o direito é entendido como expressão integral da sociedade, fato que, segundo Gramsci (2007, p. 249) é "falso", pois o direito exprime os interesses da classe dirigente e "impõe’ a toda sociedade aquelas normas de conduta que estão mais ligadas à sua razão de ser e ao seu desenvolvimento.”

A função máxima do direito é esta: pressupor que todos os cidadãos devem aceitar livremente o conformismo assinalado pelo direito, de vez que todos podem se tornar elementos da classe dirigente; no direito moderno, portanto, está implícita a utopia democrática do século XVIII. (GRAMSCI, 2007, p. 249).

A democracia burguesa, portanto, expressa a hegemonia de determinada classe sobre o conjunto de toda a sociedade e indica para a utopia de que todos podem se tornar dirigentes sem que seja alterada a estrutura econômica que fundamenta a produção capitalista. Nesse sentido, a democracia burguesa se fundamenta no princípio de igualdade sem considerar as desigualdades sociais. 
Nesse contexto, a gestão democrática também se apresenta eivada de contradições, visto que é "submetida às condições históricas da formação econômica, social e política dessa sociedade.” (SCHLESENER, 2018, p. 64). Por isso, quando se discute democracia e gestão democrática, é necessário estabelecer quais fundamentos as justificam, pois, conforme tais fundamentos, a defesa da democracia e da gestão democrática pode estar comprometida com a consolidação e a reprodução do poder ou com a transformação da ordem estabelecida.

A ordem estabelecida na sociedade capitalista está vinculada à hegemonia da classe dominante. Romper com essa ordem pode representar um verdadeiro exercício revolucionário, pois se compromete com a possibilidade de luta por outra hegemonia, ou seja, a hegemonia da classe trabalhadora. No campo da educação, defender a gestão democrática em uma perspectiva não burguesa, mas social, pode representar o grande avanço para a organização e a oferta da educação. A gestão democrática de caráter social tem o compromisso não apenas com a representatividade (democracia burguesa), mas com a participação ampla não somente de um grande número de pessoas, mas com aquelas que defendam os interesses e as necessidades da maioria da população e, consequentemente, tenham o compromisso com a transformação da ordem.

A transformação da ordem capitalista pressupõe a superação da desigualdade, sem a qual é impossível abordar a democracia social. Entretanto, a superação da desigualdade requer o reconhecimento de sua existência, de que há dirigentes e dirigidos, opressores e oprimidos, burgueses e trabalhadores, ou seja, que a luta de classes é real. Nessa perspectiva, a assertiva de que: "todos os homens são intelectuais, mas nem todos os homens têm na sociedade a função de intelectuais" (GRAMSCI, 2006, p. 18), precisaria ser tomada como premissa para a discussão sobre qual democracia e qual gestão democrática se defende.

Para tanto, a democracia, na perspectiva social aqui abordada, precisa oferecer experiência democrática de modo que os sujeitos adquiram "uma consciência responsável dos deveres que incumbem às classes que chegam ao poder" (GRAMSCI, 2004. p. 246). Essa consciência só é possível se os sujeitos estiverem vinculados a um processo de formação que faça emergir suas necessidades e libertá-los das limitações impostas pela classe dominante. Assim, o processo democrático precisa prepará-los e capacitá-los para o exercício do poder, de modo a difundir uma consciência de deveres e de direitos a partir da "experiência viva e histórica” (GRAMSCI, 2004, p. 246). Assim, a democracia social ultrapassa a democracia burguesa por romper com o invólucro da divisão social do trabalho (e todos os seus entraves) e põe em destaque as necessidades comuns e universais. Essa possibilidade de vivência democrática materializa-se por meio de práticas que se fundamentem no "trabalho coletivo e solidário acompanhado pelo debate 
político", comprometido com "um processo de educação mútua”, possibilitando "romper com as relações e valores que sustentam a sociedade capitalista baseada na livre concorrência, na competição e no individualismo." (SCHLESENER, 2018, p. 76).

A partir dos pressupostos da democracia burguesa e da democracia social é possível inferir que a gestão democrática da e na educação não ocorre sem conflitos teóricos e práticos, pois está permeada pela concepção de mundo sobre a qual se assenta a sua organização em dado momento histórico e político. Por isso, ao tratarmos sobre a gestão democrática do ensino em municípios brasileiros, é tarefa controversa, pois a realidade imediata é caótica e pode não se apresentar com a clareza necessária para a análise. Em contrapartida, podemos indicar que a gestão democrática como integrante da democracia social não pode prescindir do compromisso com a transformação da realidade e, para isso, "implica a participação efetiva das massas, a sua autonomia construída a partir de um trabalho coletivo e a possibilidade de acesso dos dirigidos a dirigentes." (SCHLESENER, 2018, p. 83).

Para além da lógica formal, com a apresentação de pressupostos legais que a asseguram, procuramos apresentar a previsão de gestão democrática do ensino público no Brasil e as contradições da realidade em que se pretende efetivála.

\section{GESTÃO DEMOCRÁTICA: POSSIBILIDADES E LIMITES DA E NA REALIDADE}

A gestão democrática do ensino público no Brasil já foi amplamente debatida por inúmeros pesquisadores e estudiosos do assunto. Não pretendemos retomar essa discussão, visto que, desde o processo de redemocratização pósditadura militar e a promulgação da Constituição Federal de 1988, esse assunto assumiu centralidade no debate a respeito da temática.

$\mathrm{Na}$ abordagem materialista histórica e dialética, a discussão sobre gestão democrática está amplamente vinculada ao exercício do poder em determinado momento histórico e se materializa pela relação de forças no interior da luta de classes, pois a gestão democrática é resultado da estrutura econômica sob a qual se vive e de todas as relações que ocorrem nesse âmbito. Com a clareza necessária de que na atual forma de sociabilidade a democracia existente está vinculada aos pressupostos burgueses, e que a democracia social existe como possibilidade histórica, apresentamos a realidade brasileira e paranaense sobre a qual se assentam as ações para a implementação da gestão democrática da e na educação. 
Segundo Oliveira (2003), o Brasil pode ser caracterizado como um "ornitorrinco", pois convive com contradições internas que expressam um desenvolvimento truncado e disforme: é altamente urbanizado, mas conta com pouca força de trabalho e a população do campo convive com forte agronegócio; um setor industrial avançado, porém carente de tecnologia molecular-digital; estrutura de serviços diversificada (para altas rendas), mas também primitiva (para os pobres); sistema financeiro atrofiado, que financia a circulação de mercadorias, seja por meio de incentivos para a acumulação de capital ou para o consumo da população. Segundo o autor, "esta é a descrição de um animal cuja 'evolução' seguiu todos os passos da família! Como primata ele já é quase Homo sapiens!” (p. 133). Essas características colocam o país em destaque, evidenciando a distância abissal entre as classes sociais:

O ornitorrinco é uma das sociedades capitalistas mais desigualitárias - mais até que as economias mais pobres da África que, a rigor, não podem ser tomadas como economias capitalistas -, apesar de ter experimentado as taxas de crescimento mais expressivas em período longo, sou tentado a dizer com elegância francesa, et pour cause. (OLIVEIRA, 2003, p. 143).

Essa realidade econômica, apontada por Oliveira (2003), influencia todos os setores e reflete nas oportunidades de participação política, na qual grande parte da população é excluída, prevalecendo os interesses dominantes. A realidade paranaense expressa também as características nacionais, em especial aquelas relacionadas ao forte agronegócio em detrimento ao trabalho de pequenos produtores, incentivos fiscais às grandes indústrias para a manutenção parca de empregos formais, além da forte influência de determinadas famílias nas políticas locais. Segundo Oliveira $(2001,2007)$, a política paranaense está, há quase três séculos, sob o domínio de determinados grupos familiares que detêm não apenas o poder político no estado, mas também o econômico. Há, portanto, na realidade local, uma intrincada rede de relações familiares e de riqueza que comandam a política estadual e municipal em todos os cantos do estado. Tal situação impede ou determina a participação do cidadão comum nos processos decisórios. Nesse contexto, o exercício da democracia é prejudicado e evidencia a fragilidade para a efetivação de ações que possibilitem um processo democrático formativo.

Fica evidenciado que os pressupostos burgueses se potencializam em todo o terreno social e se materializam em ações. Por um lado, a sociedade política age por meio de elaboração do aparato jurídico-normativo, o qual fundamenta e justifica ações e políticas governamentais, enquanto a sociedade civil não apenas influencia essa elaboração, como também a valida, universalizando para a classe 
trabalhadora os projetos da classe dominante. No caso brasileiro (e paranaense), essa situação aprofunda-se e amplia-se em razão de questões históricas e das características conservadoras que a mantêm.

O papel conservador do Estado brasileiro deriva dos imperativos de assegurar relações de dominação, reproduzir o modo de exploração e preservar os padrões existentes de desigualdade de renda, riqueza e privilégio, independentemente do desempenho econômico. (SAAD FILHO; MORAIS, 2018, p. 26, grifo dos autores).

As realidades nacional e local demonstram que são contraditórias e isso colabora para o domínio do poder econômico sobre toda a sociedade. A gestão democrática não é isenta de tais influências e interesses, demonstrando o quão frágil pode ser o exercício da democracia para aqueles que não fazem parte desse seleto grupo.

Embora a Constituição de 1988 esteja pautada em princípios democráticos e assegure a existência de instituições democráticas (art. 90, II; art. 127; art. 194; art. 206, VI; art. 216-A, X, entre outras previsões), a efetivação de tais canais de participação ainda estão fadados aos limites dos interesses dos grupos no poder em determinado momento histórico. Isso se evidenciou fortemente, quando em 2019, o presidente da República, Jair Messias Bolsonaro, limitou a existência de Colegiados na Administração Pública Federal, por meio do decreto no 9.759, de 11 de abril de $2019^{1}$ (BRASIL, 2019). É importante destacar que esses colegiados se caracterizavam como importantes mecanismos de participação popular e de gestão democrática sobre políticas públicas.

Em relação à importância de um princípio constitucional, Adrião e Camargo (2001, p. 72) esclarecem que:

O termo princípio é empregado para designar, na norma jurídica escrita, os postulados básicos e fundamentais presentes em todo Estado de direito, ou seja, são afirmações gerais no campo da legislação a partir das quais devem decorrer as demais orientações legais. [...] Ao menos formalmente, podemos dizer que sua importância reside no fato de que, por se constituírem nas diretrizes das futuras normatizações legais, os princípios não podem ser desrespeitados por qualquer medida governamental ou pela ação dos componentes da sociedade civil, tornando uma espécie de referência para validar legalmente as normas que dele derivam.

\footnotetext{
1 O referido decreto encontra-se sob judice, por meio de Ação Direta de Inconstitucionalidade, em tramitação no Supremo Tribunal Federal (STF). Em 13 de junho de 2019, o STF proferiu decisão em medida liminar, limitando o alcance do referido decreto.
} 
Os princípios constitucionais que sustentam a organização social e política brasileira não são previsões abstratas que podem ou não ser observadas, mas se caracterizam como observância obrigatória a ser seguida, independentemente do grupo que exerce o poder. No entanto, como já observado sobre democracia e gestão democrática, tais princípios sofrem interpretação conforme as concepções e/ou entendimento do grupo hegemônico que exerce o poder em determinado momento histórico. Por isso, o exercício da democracia e a efetivação da gestão democrática são limitados por tais concepções, as quais não deixam de estar circunscritas na defesa de ações democráticas, mesmo quando estão contrapostas.

No campo da educação, a Constituição Federal prevê que o ensino no Brasil será ministrado com base em vários princípios, entre os quais a "gestão democrática do ensino público, na forma da lei" (BRASIL, 1988). A gestão democrática do ensino, na qualidade de princípio constitucional, também expressa a hegemonia de determinados grupos na elaboração da Constituição, visto que a opção foi democratizar a gestão apenas no setor público, relegando à Lei de Diretrizes e Bases sua regulamentação, fato que expressou a força política do setor privado, o qual, de maneira ampla, opta pela defesa de uma gestão pautada em princípios empresariais que se fundamentam na defesa da acumulação capitalista. Embora a previsão da gestão democrática do ensino público possa ser apontada como um avanço para o exercício da democracia, também expressa um entrave para sua efetivação no ensino privado.

Ao delegar a regulamentação da gestão democrática do ensino para a legislação infraconstitucional, a operacionalização do princípio ficou, posteriormente, prevista no texto da lei no 9.394, de 20 de dezembro de 1996 - Lei de Diretrizes e Bases da Educação Nacional. Essa lei prevê a gestão democrática em vários dispositivos (inciso VIII do art. 3º, artigos 14, 15 e 56), os quais abrangem toda a organização educacional pública, desde a educação básica até a superior (BRASIL, 1996). A operacionalização da gestão democrática, circunscrita à autonomia (pedagógica, administrativa e financeira) dos estabelecimentos e entes da administração pública, é prevista na lei no 9.394/1996, como participação dos profissionais da educação e da comunidade escolar e local na elaboração do projeto pedagógico da escola e conselhos escolares, respectivamente. Na educação superior, a gestão democrática está assegurada, conforme previsão no art. 56, na "existência de órgãos colegiados deliberativos, de que participação os segmentos da comunidade institucional, local e regional.” (BRASIL, 1996, s/ pág.).

Além dessas questões, é preciso apontar que a lei no 9.394/1996 também delega aos sistemas de ensino a definição de normas de gestão democrática na educação básica, conforme as peculiaridades locais (BRASIL, 1996). Embora tais previsões apontem para a descentralização da definição de normas, conforme 
as necessidades locais, essas questões também inferem que a definição local será marcada (e definida) por interesses dos grupos dominantes. Em um país marcado pelo clientelismo, pelo conservadorismo e pela defesa de interesses particulares, tal previsão pode ser permeada por contradições: embora permita que sejam tomadas decisões mais próximas da realidade, estas podem ser subsumidas por defesas distantes das reais necessidades da maioria da população. Apesar dos limites de toda ordem, há também possibilidades que não podem ser ignoradas.

A democracia, então, precisa ser entendida tanto como princípio quanto método, para que não incorra em maiores limites do que possibilidades.

A democracia como princípio articula-se ao da igualdade ao proporcionar, a todos os integrantes do processo participativo, a condição de sujeitos expressa no seu reconhecimento como interlocutor válido. Como método, deve garantir a cada um dos participantes igual poder de intervenção e decisão, criando mecanismos que facilitem a consolidação de iguais possibilidades de opção e ação diante dos processos decisórios. (ADRIÃO; CAMARGO, 2001, p. 77).

Tendo por base as questões apontadas, a efetivação da gestão democrática em municípios paranaenses é também assunto controverso, visto que, nas realidades locais, sua efetivação também é marcada por concepções e interesses políticos e sociais antagônicos. As realidades são diversas e expressam as condições materiais sob as quais vivem os sujeitos que delas fazem parte.

Para elucidar os limites e as possibilidades para a efetivação da gestão democrática, apresentamos dados sobre como a questão está posta em municípios paranaenses que já declararam legalmente sua autonomia na gestão da educação municipal, ou seja, já instituíram Sistemas Municipais de Ensino.

\section{GESTÃO DEMOCRÁTICA NA EDUCAÇÃO MUNICIPAL: DADOS DE SISTEMAS MUNICIPAIS DE ENSINO NO PARANÁ}

Compreender a dimensão e a importância da gestão democrática em Sistemas Municipais de Ensino implica ter clareza sobre o que é e o que caracteriza um sistema de ensino. Para além da polissemia do termo "sistema", a qual abarca uma série de interpretações que passam pela noção de coletivo de escolas, redes de ensino, sistema de apostilamento para o ensino, entre outras, compactuamos com a seguinte assertiva: 
[...] o conceito de sistema denota um conjunto de atividades que se cumprem tendo em vista determinada finalidade, o que implica que as referidas atividades são organizadas segundo normas que decorrem dos valores que estão na base da finalidade preconizada. Assim, sistema implica organização sob normas próprias (o que lhe confere um elevado grau de autonomia) e comuns (isto é, que obrigam a todos os seus integrantes). (SAVIANI, 1999, p. 121).

A Constituição Federal de 1988, sob os desígnios do Estado democrático de direito, que tem como pressuposto a democracia, além de dispor sobre a gestão democrática, indicou em seu art. 211: "A União, os Estados, o Distrito Federal e os Municípios organizarão em regime de colaboração seus sistemas de ensino." (BRASIL, 1988, p. 139). A lei no 9.394/1996 reafirmou a previsão constitucional em seu art. $8^{\circ}$ e estabeleceu algumas normas para a efetivação dos Sistemas Municipais de Ensino em seu art. 11, segundo o qual os municípios terão as seguintes incumbências: "organizar, manter e desenvolver os órgãos e instituições oficiais dos seus sistemas de ensino; [...] baixar normas complementares para o seu sistema de ensino [...] e, autorizar, credenciar e supervisionar os estabelecimentos do seu sistema de ensino.” (BRASIL, 1996, s/pág.). Além disso, o parágrafo único do mesmo artigo prevê a opção municipal em constituir sistema próprio ou integrar-se ao "sistema estadual de ensino ou compor com ele um sistema único de educação básica." (BRASIL, 1996, s/pág.). Disso denota-se de forma clara a competência municipal para instituir seu sistema próprio de ensino, questão que coloca em relevo a sua autonomia em relação ao compromisso de gerir as questões educacionais.

A opção de instituir Sistema Municipal de Ensino, atrelada à efetivação da gestão democrática do ensino público pode indicar possível promoção e ampliação da participação da comunidade local para a gestão da educação. A existência de Sistemas Municipais de Ensino não garante mais envolvimento da sociedade na condução das políticas educacionais, mas representa possibilidade real de que isso aconteça, mesmo que a questão esteja visceralmente ligada à dominação política, econômica e cultural que permeia as relações locais. Entretanto, a instituição de Sistema Municipal de Ensino não se dá de forma imediata, necessitando de ações do poder público municipal para que a previsão legal se torne real. $\mathrm{O}$ reconhecimento jurídico e social de um Sistema Municipal de Ensino necessita do cumprimento de determinado trâmite, sem o qual o processo de autonomia a ser instituído é deveras comprometido: 
a) criação do Sistema Municipal de Ensino por meio de Lei Municipal específica;

b) criação ou reorganização do Conselho Municipal de Educação, de modo que se torne o órgão normativo do Sistema Municipal de Ensino; c) organização de aparato administrativo que possibilite a operacionalização do Sistema Municipal (previsão e destinação de recursos financeiros, estruturais e humanos); e, por fim, d) comunicação à Secretaria Estadual e ao Conselho Estadual de Educação sobre a aprovação das Leis específicas, visando oficializar sua desvinculação do Sistema Estadual de Ensino (em razão de que, historicamente, os municípios e suas escolas compunham o Sistema Estadual de Ensino). (FLACH, 2019, p. 8).

A partir dos caminhos escolhidos pelos municípios, podemos identificar sua opção pela autonomia ou vinculação ao Sistema Estadual de Ensino. No estado do Paraná, esse processo pode ser considerado como bastante tímido, visto que apenas 4\% dos municípios fizeram essa opção, pois, dos 399 municípios, apenas 16 constituíram legalmente seus sistemas próprios e criaram ou reorganizaram seus Conselhos Municipais de Educação. Entretanto, mesmo tendo sido criado o Sistema Municipal de Ensino e (re)organizado o Conselho Municipal de Educação para que este se torne órgão normativo, a operacionalização do sistema de forma autônoma ainda é frágil, pois não há previsão de mecanismos institucionais ${ }^{2}$ para seu funcionamento, conforme pode ser observado no Quadro 1.

\section{Quadro 1 - Situação de municípios paranaenses quanto à criação e à organização para funcionamento do Sistema Municipal de Ensino - 2018}

\begin{tabular}{|c|c|c|c|}
\hline Município & $\begin{array}{l}\text { Criação do Sistema } \\
\text { Municipal }\end{array}$ & $\begin{array}{c}\text { Criação e/ou reorganização } \\
\text { do CME }\end{array}$ & $\begin{array}{c}\text { Previsão de mecanismos } \\
\text { para a operacionalização } \\
\text { do SME }\end{array}$ \\
\hline Chopinzinho & Lei $n^{\circ} 02$, de 20/12/2001 & Lei n 1.678 , de 16/05/2001 & Sim \\
\hline Toledo & Lei no 1.857 , de 18/12/2002 & Lei n² 2.026, de 9/04/2010 & Sim \\
\hline Londrina & Lei n 9.012, de 23/12/2002 & Lei no 1.126, de 06/06/2011 & Sim \\
\hline Ponta Grossa & Lei n 7.081, de 30/12/ 2002 & Lei no 10.593, de 26/06/2011 & Sim \\
\hline Ibiporã & Lei no 1.891, de 30/06/2004 & Lei n 1.891 , de 30/06/2004 & Não \\
\hline São José dos Pinhais & Lei $n^{0} 632$, de 29/10/2004 & Lei n 632, de 29/10/2004 & Sim \\
\hline Guarapuava & Lei no 1.394 , de 8/10/2004 & Lei n 1.319 , de 10/02/2004 & Sim \\
\hline Araucária & Lei n 1.528 , de 2/12/2004. & Lei n 1.527 , de 2/12/2004 & Sim \\
\hline Curitiba & Lei $n^{0} 12.090$, de 19/12/2006 & Lei no 12.081, de 19/12/2006 & Sim \\
\hline
\end{tabular}
autorização de funcionamento e credenciamento de instituições de ensino integrantes do Sistema Municipal de Ensino, bem como recursos estruturais e financeiros para que isso aconteça, de forma que ocorra a desvinculação do sistema estadual. 


\section{Quadro 1 - Situação de municípios paranaenses quanto à criação e à organização para funcionamento do Sistema Municipal de Ensino - 2018}

\begin{tabular}{|c|c|c|c|}
\hline Município & $\begin{array}{l}\text { Criação do Sistema } \\
\text { Municipal }\end{array}$ & $\begin{array}{c}\text { Criação e/ou reorganização } \\
\text { do CME }\end{array}$ & $\begin{array}{c}\text { Previsão de mecanismos } \\
\text { para a operacionalização } \\
\text { do SME }\end{array}$ \\
\hline Paranaguá & $\begin{array}{l}\text { Lei complementar } n^{\circ} 69 \text {, de } \\
10 / 09 / 2007\end{array}$ & Lei n² 2.759, de 29/05/2007 & Sim \\
\hline Sarandi & Lei n 1.531 , de 16/06/2008 & Lei n 1.531 , de 16/06/2008 & Sim \\
\hline Pinhais & Lei n 1.059, de 28/12/2009 & Lei 1.055 , de 23/12/2009 & Sim \\
\hline Cascavel & Lei n 5.694, de 22/12/2010 & Lei n 5.694, de 22/12/2010 & Sim \\
\hline Iguatu & Lei n 620 , de 03/04/2013 & Lei nº 620, de 03/04/2013 & Não \\
\hline Palmeira & Lei n 3.592, de 13/12/2013 & Lei 3.591 , de $13 / 12 / 2013$ & Não \\
\hline Telêmaco Borba & Lei $n^{0} 2.153$, de 24/10/2016 & Lei n² 2.153, de 24/10/2016 & Não \\
\hline
\end{tabular}

Fonte: Elaboração própria com base nos dados disponibilizados nos sites das prefeituras e câmaras municipais dos municípios pesquisados.

A criação de Sistema Municipal de Ensino pode indicar intenções políticas e sociais que vislumbrem o compromisso com uma gestão mais próxima da comunidade local. No entanto, tal previsão, por si só não é indicativo de gestão democrática, pois a organização de um Sistema Municipal de Ensino que tenha sustentação em perspectivas democráticas precisa ter, no mínimo: um Conselho Municipal de Educação, livre de amarras políticas locais, com funções deliberativas e normativas, composto por membros que representem diferentes segmentos sociais; equipe de profissionais habilitados para apoio e manutenção das atividades específicas de um Sistema Municipal de Ensino (responsáveis pela autorização de funcionamento e credenciamento de instituições escolares, bem como sua fiscalização); aparato legal e normativo que assegure ações e exercício de democracia no interior do Sistema Educacional e das unidades escolares, tais como Conselhos Escolares ou equivalentes e designação de diretores de escolas que possibilitem a participação da comunidade escolar no planejamento, no acompanhamento e na avaliação das ações educacionais.

Quanto à composição dos Conselhos Municipais de Educação, todos os municípios integrantes da pesquisa preveem a participação de diferentes segmentos da sociedade. No entanto, há já algumas peculiaridades: no município de Guarapuava a indicação dos membros é realizada pelo prefeito a partir de uma lista tríplice, indicada pelos segmentos (GUARAPUAVA, 2004); em Ibiporã, $50 \%$ dos membros são de nomeação exclusiva do prefeito (IBIPORÃ, 2004); em São José dos Pinhais, a presidência é de nomeação exclusiva do Poder Executivo Municipal (SÃO JOSÉ DOS PINHAIS, 2004); e, em Chopinzinho, o secretário de Educação é o presidente nato desse órgão colegiado (CHOPINZINHO, 2001). 
Tais previsões podem indicar que o poder público local exerce influência direta nas decisões e nas deliberações, fato que pode prejudicar o exercício da democracia, corroborando o domínio de determinados grupos nos encaminhamentos políticos locais. Todos os Conselhos Municipais de Educação têm funções deliberativas sobre os encaminhamentos políticos, principalmente aquelas relacionadas ao acompanhamento das políticas e dos programas propostos pelo poder público municipal, mas a função normativa relativa às atividades de um sistema municipal em efetivo funcionamento são ausentes em quatro municípios investigados, o que denota, ainda, dependência e vinculação às normas do Sistema Estadual de Ensino. Essa questão também pode ser um possível indicativo da falta de autonomia ou mesmo submissão às orientações mais gerais.

Em relação à designação de diretores de estabelecimentos escolares, dos 16 municípios pesquisados, em três não foram localizados documentos normativos sobre essa possibilidade de exercício democrático. Nos demais, há documentos norteadores para a designação de diretores, dos quais, em 12, há previsão de escolha pela comunidade escolar; e, em um, a escolha de diretores escolares será realizada pelo prefeito, sendo essa função entendida como Cargo em Comissão (PALMEIRA, 2016). Nos municípios com previsão de escolha de diretor pela comunidade escolar, em sete há paridade de participação da comunidade interna e externa no Colegiado Eleitoral. Quanto à participação da comunidade interna em Cascavel, há inclusão de estagiários (CASCAVEL, 2014); em Araucária, há previsão de participação de alunos com idade "igual ou maior que 12 anos" (ARAUCÁRIA, 2009). Tais previsões indicam maior amplitude na participação da comunidade, possibilitando que mais sujeitos vivenciem o processo democrático.

Em que pese a importância da participação da comunidade escolar na definição, no acompanhamento, na execução e na avaliação de ações nas unidades escolares, a previsão de funcionamento de conselhos escolares ou equivalentes ainda também é frágil nos municípios pesquisados, visto que em apenas 10 deles há normas específicas para seu funcionamento.

Tais fatos, relativos às possibilidades de efetivação da gestão democrática, indicam que, em municípios que declararam o compromisso com a autonomia para a gestão das políticas locais, a efetivação da gestão democrática não está consolidada. Todavia, a iniciativa de criação de Sistemas Municipais de Ensino precisa ser entendida como avanço na busca por vivências democráticas. Em contexto conservador e de controle político e econômico por determinados grupos, essa iniciativa, mesmo que limitada, precisa ser comemorada. 


\section{CONSIDERAÇÕES FINAIS}

No atual estágio do capitalismo, em que se faz presente fortemente a divisão social e a exploração do trabalho humano, a discussão a respeito das possibilidades e dos limites de vivência democrática e efetivação de gestão educacional pautada em seus princípios se mostra bastante contraditória, visto que os dois termos - democracia e gestão educacional - são carregados de significados, compromissos, interesses e ideologias. A divisão da sociedade também se expressa na interpretação e na defesa da democracia, pois, por um lado, a democracia burguesa se mostra hegemônica e sob a égide da representatividade, marcada pelo domínio de determinado grupo que se encontra no centro do modo de produção e, consequentemente, na condução de políticas educacionais. Por outro lado, mesmo sob os limites do capitalismo, as brechas deixadas pelos grupos dominantes para a participação popular evidenciam possibilidades de luta hegemônica por outra forma de democracia, a qual se vincula a outra sociabilidade que tenha como pressuposto a superação da divisão de classes. Todavia, é preciso reconhecer os limites para que essa possibilidade não fique no campo da utopia e se torne real. Por isso, mesmo sob forte pressão dos interesses dominantes, a defesa da democracia popular e da gestão democrática, pautada em seus pressupostos, precisa ser presente.

$\mathrm{Na}$ realidade brasileira e paranaense, a vivência da democracia enfrenta entraves, tanto em razão dos interesses hegemônicos quanto pelo resultado das influências históricas, sociais e culturais, as quais dão um contorno conservador para a condução de políticas públicas. Nesse sentido, os dados analisados evidenciam o quão distante a educação paranaense se encontra de uma gestão democrática, pautada em princípios da democracia popular. Contudo, os dados dos municípios analisados demonstram que, além de limites, há possibilidades para que a gestão democrática deixe de ser apenas previsão legal e se torne real, mesmo que embasada em pressupostos burgueses. Quanto à criação de Sistemas Municipais de Ensino e indicativos de gestão democrática na condução da educação local, a realidade paranaense expressa fragilidades e potencialidades.

A utopia de alcançar formas de efetivação ou de aproximação de uma democracia popular é possibilidade histórica. Entretanto, a vivência de uma gestão democrática pautada na democracia burguesa não pode ser abandonada, pois ela deixa brechas para o exercício democrático e abre caminhos para a luta por outra hegemonia que tenha a igualdade, a liberdade e a justiça social como fundamentos. 


\section{REFERÊNCIAS}

ADRIÃO, T.; CAMARGO, R. B. A gestão democrática na Constituição Federal de 1988. In: OLIVEITA, R. P.; ADRIÃO, T. (org.). Gestão, Financiamento e direito à Educação: análise da LDB e da Constituição Federal. São Paulo: Xamã, 2001. p. 69-78.

ARAUCÁRIA. Lei $\mathbf{n}^{\mathbf{0}} \mathbf{2 . 0 6 0}$, de 15 de outubro de 2009. Dispõe sobre a eleição direta de diretores e Diretores auxiliares nas unidades educacionais da rede pública municipal de Ensino e dá outras providências. 2009. Disponível em: https:// leismunicipais.com.br/pdf/Lei-ordinaria-2060-2009-Araucaria-PR.pdf. Acesso em: 20 abr. 2018.

BRASIL. [Constituição (1988)]. Constituição da República Federativa do Brasil. Brasilia, DF: Senado, 1988.

BRASIL. Lei $\mathrm{n}^{\circ}$ 9.394, de 20 de dezembro de 1996. Estabelece as diretrizes e bases da educação nacional. Brasília: Presidência da República, Casa Civil, Subchefia para Assuntos Jurídicos, [1996]. Disponível em: http://www.planalto. gov.br/ccivil_03/leis/19394.htm. Acesso em: 18 jul. 2018.

BRASIL. Decreto $\mathbf{n}^{\circ} \mathbf{9 . 7 5 9}$, de 11 de abril de 2019. Extingue e estabelece diretrizes, regras e limitações para colegiados da administração pública federal. Brasília: Presidência da República, Casa Civil, Subchefia para Assuntos Jurídicos, [2019]. Disponível em: http://www.planalto.gov.br/ccivil_03/_ato20192022/2019/decreto/D9759.htm. Acesso em: 18 jul. 2018.

CASCAVEL. Lei $\mathbf{n}^{\mathbf{0}} \mathbf{6 . 4 0 7}$, de 20 de outubro de 2014. Dispõe sobre a Escolha de Diretores das Escolas Municipais e dos Centros Municipais de Educação infantil de Cascavel, mediante eleição direta para mandato de dois anos. 2014. Disponível em: https://leismunicipais.com.br/pdf/Lei-ordinaria-6407-2014-Cascavel-PR. pdf. Acesso em: 20 abr. 2018.

CHEPTOLIN, A. A dialética materialista: categorias e leis da dialética. São Paulo: Alfa-Omega, 1982. 
CHOPINZINHO. Lei complementar $\mathrm{n}^{\circ}$ 02, de 20 de dezembro de 2001. Autoriza o chefe do poder executivo a criar o Sistema Municipal de Ensino de Chopinzinho. 2001. Disponível em: http://www.camarachopinzinho.pr.gov.br/ leis/1475064857.pdf. Acesso em: 22 jan. 2018.

DIAS, E. F. Notas sobre hegemonia. In: SCHLESENER, A. H. et al. Filosofia, política e educação: leituras de Antonio Gramsci. Curitiba: UTP, 2014. p. 19- 34.

FLACH, S. F. A gestão democrática nos sistemas municipais de ensino do Paraná: uma análise a partir dos conselhos municipais de educação. Ensaio: Avaliação e Políticas Públicas em Educação, Rio de Janeiro, ahead of print, 2019.

GRAMSCI, A. Democracia operária. In: GRAMSCI, A. Escritos Políticos. Rio de Janeiro: Civilização Brasileira, 2004. v. 1. p. 245 -249.

GRAMSCI, A. Cadernos do Cárcere. 4. ed. Rio de Janeiro: Civilização Brasileira, 2006. v. 2.

GRAMSCI, A. Cadernos do Cárcere. 3. ed. Rio de Janeiro: Civilização Brasileira, 2007. v. 3.

GUARAPUAVA. Lei no $\mathbf{1} .394$, de 8 de outubro de 2004. Disciplina a organização do Sistema Municipal de Ensino do município de Guarapuava, e dá outras providências. 2004. Disponível em: https://leismunicipais.com.br/a/pr/g/ guarapuava/lei-ordinaria/2004/140/1394/lei-ordinaria-n-1394-2004-disciplinaa-organizacao-do-sistema-municipal-de-ensino-do-municipio-de-guarapuava-eda-outras-providencias?q=1394. Acesso em: 10 out. 2018.

IBIPORÃ. Lei $\mathbf{n}^{\mathbf{0}} \mathbf{1 . 8 9 1}$, de 30 de junho de 2004. Disciplina a organização do Sistema Municipal de Ensino do Município de Ibiporã e dá outras providências. 2004. Disponível em: http://www.cmibipora.pr.gov.br/index2.php?pag=T0dRP U9EZz1PR009T0RRPU9Eaz1PR009T1dJPU9HRT1PVFU9T1RNPU9UQT1Z VEE9\&\&id=5062. Acesso em: 12 out. 2018.

OLIVEIRA, F. Crítica à razão dualista / O ornitorrinco. São Paulo: Boitempo, 2003.

OLIVEIRA, R. C. de. O silêncio dos vencedores: genealogia, classe dominante e estado no Paraná. Curitiba: Moinho do Verbo, 2001. 
OLIVEIRA, R. C. de. Famílias, poder e riqueza: redes políticas no Paraná em 2007. Sociologias, Porto Alegre, n. 18, p. 150-169, dez. 2007.

PALMEIRA. Lei municipal $\mathrm{n}^{\circ}$ 4.133, de 17 de maio de 2016. Institui o Plano de Cargos, Carreira e Salários do quadro próprio do magistério público municipal e dá outras providências. Disponível em: https://leismunicipais.com.br/a/pr/p/ palmeira/lei-ordinaria/2016/413/4133/lei-ordinaria-n-4133-2016-institui-oplano-de-cargos-carreira-e-salarios-do-quadro-proprio-do-magisterio-publicomunicipal-e-da-outras-providencias. 2016. Acesso em: 6 jan. 2019.

SAAD FILHO, A.; MORAIS, L. Brasil: neoliberalismo versus democracia. São Paulo: Boitempo, 2018.

SÃO JOSÉ DOS PINHAIS. Lei $\mathbf{n}^{\mathbf{0}}$ 632, de 29 de outubro de 2004. Disciplina a organização do Sistema Municipal de Ensino do município de São José dos Pinhais. 2004. Disponível em: https://leismunicipais.com.br/a/pr/s/sao-josedos-pinhais/lei-ordinaria/2004/64/632/lei-ordinaria-n-632-2004-disciplina-aorganizacao-do-sistema-municipal-de-ensino-do-municipio-de-sao-jose-dospinhais?q=632. Acesso em: 18 out. 2016.

SAVIANI, D. Sistemas de ensino e planos de educação: o âmbito dos municípios. Educação \& Sociedade, Campinas, v. 20, n. 69, p. 119-136, dez. 1999.

SCHLESENER, A. H. "Esta mesa redonda é quadrada": notas sobre gestão democrática a partir dos escritos de Antonio Gramsci. In: SCHLESENER, A. H.; OLIVEIRA, A. L.; ALMEIDA, T. M. G. (org.). A atualidade da filosofia da práxis e políticas educacionais. Curitiba: UTP, 2018. p. 63-86.

\section{Simone de Fátima Flach}

Doutora em Educação (UFSCAR). Docente do Departamento de Educação e do Programa de Pós-Graduação em Educação da Universidade Estadual de Ponta Grossa - UEPG. Diretora da Associação Nacional de Política e Administração da Educação - ANPAE/PR. E-mail: eflach@uol.com.br 